\title{
Presence of gustatory and olfactory dysfunction in the time of the COVID-19 pandemic
}

\author{
Alexander Kusnik ${ }^{1,2}$, Christel Weiss ${ }^{3}$, Melanie Neubauer ${ }^{1}$, Bianca Huber ${ }^{1}$, Marlis Gerigk ${ }^{4}$, Thomas Miethke $e^{4,5}$, \\ Nicole Hunter ${ }^{4}$, Nicole Rotter ${ }^{6}$, Sonja Ludwig ${ }^{6}$, Angela Schell ${ }^{6}$, Matthias P. Ebert ${ }^{1,2}$ and Andreas Teufel ${ }^{1,2,7^{*}}$
}

\begin{abstract}
Background: The unexpected outbreak of the novel severe acute respiratory syndrome coronavirus 2 (SARSCoV-2) caused more than 49 million cases and an estimated 2,000,000 associated deaths worldwide. In Germany, there are currently more than 2,000,000 laboratory-confirmed coronavirus disease 2019 (COVID-19) cases including 51,800 deaths. However, regional differences also became apparent and with the second wave of infections, the detailed characterization of COVID-19 patients is crucial to early diagnosis and disruption of chains of infections.

Methods: Handing out detailed questionnaires to all individuals tested for COVID-19, we evaluated the clinical characteristics of negative and positive tested individuals.

Expression of symptoms, symptom duration and association between predictor variables (i.e. age, gender) and a binary outcome (olfactory and gustatory dysfunction) were assessed.

Results: Overall, the most common symptoms among individuals who tested positive for SARS-CoV-2 were fatigue, headache, and cough. Olfactory and gustatory dysfunction were also reported by many SARS-CoV-2 negative individuals, more than $20 \%$ of SARS-CoV-2 negative tested individuals in our study reported olfactory and gustatory dysfunction. Independent of SARS-CoV-2 status, more females displayed symptoms of gustatory $(29.8 \%, p=0.0041)$ and olfactory dysfunction $(22.9 \%, p=0.0174)$ compared to men.

Conclusions: Bringing early SARS-CoV-2 tests to the populations at risk must be a main focus for the upcoming months. The reliability of olfactory and gustatory dysfunction in COVID-19 negative tested individuals requires deeper investigation in the future.
\end{abstract}

Keywords: COVID, COVID-19, SARS-CoV-2, Anosmia, Smell, Hyposmia, COVID-19 negative Dysgeusia, Taste, Loss, Gustatory, Olfactory, Olfaction

\footnotetext{
* Correspondence: andreas.teufel@medma.uni-heidelberg.de

'Department of Medicine II, University Medical Center Mannheim, Medical

Faculty Mannheim, Heidelberg University, Mannheim, Germany

${ }^{2}$ Clincial Cooperation Unit Healthy Metabolism, Center for Preventive

Medicine Baden-Württemberg, Medical Faculty Mannheim, Heidelberg

University, Mannheim, Germany

Full list of author information is available at the end of the article
}

(c) The Author(s). 2021 Open Access This article is licensed under a Creative Commons Attribution 4.0 International License, which permits use, sharing, adaptation, distribution and reproduction in any medium or format, as long as you give appropriate credit to the original author(s) and the source, provide a link to the Creative Commons licence, and indicate if changes were made. The images or other third party material in this article are included in the article's Creative Commons licence, unless indicated otherwise in a credit line to the material. If material is not included in the article's Creative Commons licence and your intended use is not permitted by statutory regulation or exceeds the permitted use, you will need to obtain permission directly from the copyright holder. To view a copy of this licence, visit http://creativecommons.org/licenses/by/4.0/ The Creative Commons Public Domain Dedication waiver (http://creativecommons.org/publicdomain/zero/1.0/) applies to the data made available in this article, unless otherwise stated in a credit line to the data. 


\section{Introduction}

The novel COVID-19 coronavirus infection currently causing a global pandemic may present on a spectrum from asymptomatic to severe infection affecting almost every possible organ system [1]. A more severe course of disease, with rapid deterioration and acute respiratory distress syndrome (ARDS) or even fatal outcomes were reported especially among older people or those with comorbidities [2]. The current literature estimated a mean incubation period of three to 5 days $[3,4]$. In symptomatic patients, the clinical manifestations of the disease usually started after less than 1 week [4]. However, as the virus effectively replicates in the upper respiratory tract and infected individuals produce a considerable amount of virus during a prodrome period, the infection may be spread early and index persons may be unrecognized for several days [2]. As a second wave of COVID-19 is ongoing, epidemiological studies are important in order to characterize symptoms, comorbidities, age and even country specific characteristics of the disease in order to identify infected patients as early as possible [4]. We therefore report our single center study on COVID-19 and share our detailed analysis on patient-reported symptoms, co-morbidities, and course of disease.

\section{Methods}

\section{Subjects and setting}

A questionnaire was developed according to relevant symptoms assessing general patient characteristics, severity and duration of symptoms and use of medication. It was distributed between March 31 and July 15, 2020 after COVID-19 testing to each person. Adult patients with a possible SARS-CoV-2 infection received testing via real-time reverse transcription PCR (rRT-PCR) of nasopharyngeal/oropharyngeal swabs in Mannheim, Germany. Most individuals received SARS-CoV-2 testing because of contact with people who had tested positive for SARS-CoV-2 infection, displaying symptoms likely for a SARS-CoV-2 infection, or because they had travelled in an area of high risk of exposure.

\section{Statistical methods}

Statistical Package for the Social Sciences for Windows (SPSS version 26,0; IBM Corp, Armonk, NY, USA) and SAS, release 9.4 (SAS Institute Inc., Cary, North Carolina, USA) were used to perform the statistical analyses.

In order to compare two groups regarding a binary factor (i.e. co-morbidity present or not present) Chi2 test or Fisher's exact test was performed, as appropriate. Expression of symptoms displayed by patients was categorized into none, mild, moderate, severe and very severe. For these ordinally scaled parameters an exact trend test according to Cochran-Armitage has been used.
Quantitative variables approximately normally distributed (i.e. age) have been analyzed by a 2 -sample $t$ test. Symptom duration was evaluated with the help of a Mann-Whitney-U-Test. A multiple logistic regression was performed in order to investigate the association between predictor variables (i.e. age, gender) and a binary outcome (olfactory and gustatory dysfunction). Incomplete responses were excluded from analysis. In general, the result of a statistical test has been considered as significant for $p<0.05$.

\section{Results}

\section{Demographics and clinical characteristics}

A total of 711 patients suspected of COVID-19 were included in this study, with $43(6 \%)$ patients tested positive via PCR and 668 patients (94\%) tested negative. There were 313 males and 396 females ( 2 unspecified). In the negative and positive tested subgroups, $44.4 \%$ or $39.5 \%$ of all individuals were male $(p=0.5298)$. The mean age of the SARS-CoV-2 negative tested subgroup was comparable with $40.9 \pm 14.5$ years (range 18-80) and $41 \pm$ 16.2 years (range 20-82) in the COVID-19 positive tested subgroup $(p=0.9722)$.

\section{Co-morbidity}

The most prevalent comorbidities of patients were lung disease $(77,10.8 \%)$, followed by other pre-existing diseases most commonly consisting of allergic diseases (34 patients $4.78 \%$ ), hypertension (38 patients, 5.34\%), endocrine disorders (30 patients; $4.21 \%$ ) and chronic heart disease (24 patients; 3.37\%) (Table 1).

Statistical difference in symptoms was only seen for self-reported kidney disease $(p=0.0004)$, indicating that co-morbidities were distributed similarly in positive and negative tested patients. However, among positive tested patients $63 \%$ self-reported pre-existing conditions, which was significantly higher than in the negative tested population.

\section{Clinical presentation}

Among all individuals tested, the most commonly observed symptoms were fatigue and headache (Table 2). However significant differences were observed between COVID-19 positive and negative patients. Most common symptoms among individuals tested positive for COVID19 were fatigue (91\%), headache (79\%) and cough (74\%). These symptoms were also the most common symptoms displayed in COVID-19 negative patients (fatigue (70\%), headache (63\%) and cough (57\%). Trend tests revealed statistical significance in symptoms between SARS-CoV2 positive and negative tested individuals for fever, olfactory and gustatory disturbance and fatigue (each $p<0.0001)$, headache $(p=0.0073)$ and cough $(p=$ $0.0004)$. In addition, statistical significance was seen for 
Table 1 Presence of pre-existing diseases according to COVID-19 status (n.a. = not applicable)

\begin{tabular}{llll}
\hline Variable & COVID-19 Positive & COVID-19 Negative & p-value \\
\hline Number of Patients & 43 & 668 & $156(23.35 \%)$ \\
Overall previous diseases & $27(62.79 \%)$ & $2(0.3 \%)$ & 0.0001 \\
Stroke & $1(2.33 \%)$ & $9(1.35 \%)$ & 0.1709 \\
Myocardial Infarction & $2(4.65 \%)$ & $23(3.4 \%)$ & 0.1390 \\
Chronic Heart Disease & $1(2.33 \%)$ & $8(1.2 \%)$ & 1.0000 \\
Inflammatory Bowel Disease & 0 & $14(2.10 \%)$ & 1.0000 \\
Rheumatological Disorder & $1(2.33 \%)$ & $3(0.45 \%)$ & 0.6115 \\
Transplantation & 0 & $3(0.45 \%)$ & 1.0000 \\
Kidney Disease & $4(9.30 \%)$ & 0 & 0.0004 \\
Dialysis & 0 & $1(0.15 \%)$ & n.a. \\
Autoimmune Liver Disease & 0 & $2(0.30 \%)$ & 1.0000 \\
Liver Cirrhosis & $1(2.33 \%)$ & $72(10.78 \%)$ & 0.1709 \\
Lung Disease & $5(11.63 \%)$ & $2(0.30 \%)$ & 0.8010 \\
Lupus & 0 & $34(5.1 \%)$ & 1.0000 \\
Hypertension & $4(9.30 \%)$ & $28(4.2 \%)$ & 0.2787 \\
Endocrine disorder & $2(4.65 \%)$ & $21(3.1 \%)$ & 0.7017 \\
Diabetes & $1(2.33 \%)$ & $33(4.9 \%)$ & 1.0000 \\
Allergic disorders & $1(2.33 \%)$ & $69(10.3 \%)$ & 0.7146 \\
Other & $4(9.30 \%)$ & 1.0000 \\
\hline
\end{tabular}

dyspnea $(p=0.0254)$, joint pain $(p=0.0015)$ and rhinorrhea $(p=0.0197)$.

Individuals with the relevant symptoms who tested positive for COVID-19 reported an overall longer median duration of symptoms compared to individuals tested negative for SARS-CoV-2 (Table 3). Statistical significance in the duration of symptoms between SARS-CoV-2 positive and negative tested individuals was seen for fever (3.5 days; $p=0.0004)$, olfactory disturbance (6 days; $p=0.0010)$, dyspnea (5.5 days; $p=$

Table 2 Presence of symptoms according to COVID-19 status

\begin{tabular}{llll}
\hline Variable & COVID-19 Positive & COVID-19 Negative & p-value \\
\hline Number of Patients & 43 & 668 & $21432.04 \%)$ \\
Fever $\left(>37.5^{\circ} \mathrm{C}\right)$ & $22(51.16 \%)$ & $156(23.35 \%)$ & $<.0001$ \\
Gustatory Dysfunction & $27(62.79 \%)$ & $133(19.91 \%)$ & $<.0001$ \\
Olfactory Dysfunction & $25(58.14 \%)$ & $80(11.98 \%)$ & 0.0001 \\
Visual Dysfunction & $5(11.63 \%)$ & $55(8.23 \%)$ & 0.8454 \\
Auditory Dysfunction & $2(4.65 \%)$ & $87(13.02 \%)$ & 0.4569 \\
Sensibility Dysfunction & $11(25.58 \%)$ & $267(39.97 \%)$ & 0.1353 \\
Dyspnoea & $21(48.84 \%)$ & $466(69.76 \%)$ & 0.0254 \\
Fatigue & $39(90.70 \%)$ & $419(62.72 \%)$ & 0.0001 \\
Headache & $34(79.07 \%)$ & $309(46.26 \%)$ & 0.0073 \\
Joint Pain & $26(60.47 \%)$ & $352(52.69 \%)$ & 0.0015 \\
Rhinorrhea & $28(52.69 \%)$ & $378(56.59 \%)$ & 0.0197 \\
Cough & $32(74.42 \%)$ & $360(53.89 \%)$ & 0.0004 \\
Pharyngitis & $26(60.47 \%)$ & $177(26.50 \%)$ & 0.0981 \\
Diarrhea & $14(32.56 \%)$ & $211(31.59 \%)$ & 0.8507 \\
Ocular Pruritus & $1841.86 \%)$ & $13(4.39 \%)$ & 0.4021 \\
Scrotal Pain & 0 & & 0.7031 \\
\hline
\end{tabular}


Table 3 Median duration of symptoms based on COVID-19 status (sample sizes in parentheses)

\begin{tabular}{llll}
\hline Duration in days & & & \\
\hline Symptom & $\begin{array}{l}\text { Symptoms in COVID-19 positive patients } \\
\text { (days) }\end{array}$ & $\begin{array}{l}\text { Symptoms in COVID-19 negative patients } \\
\text { (days) }\end{array}$ & p-value \\
\hline Fever $\left(>37.5^{\circ} \mathrm{C}\right)$ & $3.5(n=22)$ & $2(n=214)$ & 0.0004 \\
Olfactory Dysfunction & $6(n=25)$ & $3(n=133)$ & 0.0010 \\
Visual Dysfunction & $2(n=5)$ & $2.5(n=80)$ & 0.6739 \\
Auditory Dysfunction & $1(n=2)$ & $3(n=55)$ & 0.1734 \\
Sensibility Dysfunction & $2(n=11)$ & $2(n=87)$ & 0.1670 \\
Dyspnoea & $5.5(n=21)$ & $3(n=267)$ & 0.0355 \\
Fatigue & $5(n=39)$ & $3(n=466)$ & 0.0010 \\
Headache & $3(n=34)$ & $3(n=419)$ & 0.0567 \\
Cough & $4.5(n=32)$ & $3(n=378)$ & 0.1737 \\
Pharyngitis & $3.5(n=26)$ & $3(n=360)$ & 0.0411 \\
Diarrhea & $2(n=14)$ & $2(n=177)$ & 0.4913 \\
\hline
\end{tabular}

0.0355 ), fatigue ( 5 days; $\mathrm{p}=0.0010$ ) and pharyngitis (3, 5 days; $p=0.0411$ ).

\section{Olfactory and gustatory dysfunction symptoms}

Our questionnaire included a more detailed characterization regarding duration, onset and specifics of taste and olfactory disturbance (OGD). 62.8 and $58.1 \%$ of patients who were tested positive for SARSCoV-2 reported gustatory or olfactory disturbance, respectively. The majority of SARS-CoV-2 positive patients with a gustatory disturbance described an overall decline in taste $(46.5 \% p=0.0001)$ compared to $14.22 \%$ seen in SARS-CoV-2 negative tested patients with gustatory dysfunction (Table 4). In contrast, 23.35 and $19.91 \%$ of SARS-CoV-2 negative tested patients reported gustatory and olfactory dysfunction, respectively (Table 2). 27.5\% of patients who tested negative for SARS-CoV-2 reported OGD on a spectrum from mild to very severe (51 patients $(7.6 \%)$ only gustatory dysfunction, 28 patients (4.2\%) only olfactory dysfunction, 105 (15.7\%) with the presence of both, olfactory and gustatory dysfunction).

We also assessed the concomitant use of antiinflammatory medication (Table 5) in SARS-CoV-2 negative and positive patients. The analysis indicated that $60 \%$ of SARS-CoV-2 positive tested patients and $37 \%$ of SARS-CoV-2 negative tested patients used antiinflammatory medications $(p=0.0019)$. Ibuprofen (25.6\%) and acetaminophen (30.2\%) were the most commonly used medications in patients suffering from COVID-19. Similar findings were seen in the SARS$\mathrm{CoV}-2$ negative tested subgroup; the most commonly used medications were ibuprofen (20.5\%) and acetaminophen (13.5\%). Chemosensory complaints from drugs might present differently and might include altered sensation as bitter or metallic taste and perceptual distortions [5]. We therefore assessed for more specific taste disturbances like bitter, sour and metallic taste. A statistical significance in the mean number of taste disturbances was evident in the SARS-CoV-2 positive tested subgroup ( $\mu$ in changes of taste 0.8 versus 0.3 ; $p<0.0001$ ) (Table 4). Furthermore, we analyzed for possible other related symptoms compatible with allergies (e.g. ocular pruritus, rhinorrhea) as these conditions tend to be highly underdiagnosed [6]. Patients tested negative for SARS-CoV-2 who displayed OGD more commonly reported rhinorrhea $(72 \%, p=0.0001)$ and

Table 4 Specific description of Taste disturbance

\begin{tabular}{llll}
\hline Variable & COVID-19 Positive & COVID-19 Negative & $\boldsymbol{p}$-value \\
\hline General disturbance in taste & $27(62.79 \%)$ & $149(22.31 \%)$ & 0.0001 \\
No taste of sweet & $3(6.98 \%)$ & $18(2.69 \%)$ & 0.1280 \\
No taste of sour & $3(6.98 \%)$ & $15(2.25 \%)$ & 0.0890 \\
Only bitter taste & $2(4.65 \%)$ & $12(1.80 \%)$ & 0.2054 \\
Taste diminished & $20(46.51 \%)$ & $95(14.22 \%)$ & 0.0001 \\
Metallic taste & $2(4.65 \%)$ & $34(5.09 \%)$ & 1.0000 \\
Other taste disturbance & $4(9.30 \%)$ & $18(2.69 \%)$ & 0.0382 \\
Mean number of changes in taste & 0.8 & 0.3 & 0.0001 \\
\hline
\end{tabular}


Table 5 Usage of medication based on COVID-19 status

\begin{tabular}{llll}
\hline Variable & COVID-19 Positive & COVID-19 Negative & $p$-value \\
\hline Use of anti-inflammatory medication & $26(60.4 \%)$ & $245(36.68 \%)$ & 0.0019 \\
Ibuprofen & $11(25.6 \%)$ & $137(20.5 \%)$ & 0.4271 \\
Acetaminophen & $13(30.2 \%)$ & $90(13.5 \%)$ & 0.0025 \\
Aspirin & $1(2.3 \%)$ & $25(3.7 \%)$ & 1.0000 \\
Metamizole & $6(14.0 \%)$ & $21(3.1 \%)$ & 0.0039 \\
Diclofenac & $1(2.3 \%)$ & $1(0.1 \%)$ & 0.1174 \\
Other medication & $2(4.7 \%)$ & $29(4.3 \%)$ & 0.0027 \\
\hline
\end{tabular}

ocular pruritus $(39 \%, p=0.0164)$ compared to negative tested patients without OGD $(\mathrm{p}=0.0001)$ (Table 6). A statistical significance in the number of pre-existing diseases was evident in COVID-19 negative tested patients with OGD $(59.2 \%, p=0.0314)$, but pre-existent diseases possibly responsible for OGD like rheumatological disorders [7], stroke [8,9] or kidney disease [9] were similarly distributed between both groups.

Further analysis indicated that SARS-CoV-2 negative tested patients with OGD more commonly described other neurological dysfunction like visual $(21 \%, p=$ $0.0001)$, auditory $(20 \%, \mathrm{p}=0.0001)$, or sensibility $(21 \%$, $p=0.0003)$ disturbance compared to SARS-CoV-2 negative tested patients without OGD, raising the question for the possible mechanism of increased neurological dysfunction without evidence of viral entry. Concerning gender and age, analysis showed that independent of SARS-CoV-2 status, more females displayed symptoms of gustatory dysfunction $(29.8 \%, p=0.0041)$ and olfactory dysfunction $(22.9 \%, p=0.0174)$ compared to males. Additionally, the simultaneous occurrence of OGD was more prevalent in females $(33.08 \%)$ than males $(23.96 \%)$ with statistical significance in younger patients (Suppl. Table 1). The results of the logistic regression analysis showed that gustatory dysfunction is highly associated with gender $(p=0.0047)$, with females being more affected than men (Odds Ratio $=1.659$ ) whereas patient's age does not play an important role $(p=0.1578$, Odds Ratio $=0.991)$. In addition, occurrence of both, olfactory and gustatory dysfunction, is highly dependent on gender $(p=0.0105$, Odds Ratio $=1.549)$ and age $(p=0.0361$, Odds Ratio $=0.988$ per year), with especially young females being affected the most.

\section{Discussion}

Current evidence indicates that the clinical features of olfactory and gustatory dysfunction (OGD) might be far more prevalent in the European population than in the Asian population $[10,11]$, raising questions for possible new mutations [12], different expression of the angiotensin-converting enzyme 2 (ACE2)-entry receptor in different populations and different organs [13-15].
Neurons and glial cells express the ACE2 receptor offering a binding spot for the virus and subsequent neurological, olfactory, and gustatory dysfunction [16].

Niklassen et al. [17] assessed OGD in a total of 111 COVID-19 positive tested individuals at three different time intervals with the help of Sniffin' Sticks and taste sprays/strips. The study indicated that during the acute infection with SARS-CoV-2, 21\% of patients displayed anosmia and 49\% hyposmia, in contrast $26 \%$ showed various degrees of gustatory dysfunction. The same tests were used in a study conducted by Huart et al. [18] distinguishing possible differences in the pathophysiology of OGD in acute cold and COVID-19 patients. A comparison of OGD was made between COVID-19 infected individuals, acute cold patients in the pre- COVID-19 era, and healthy controls. Similarly, like in the study conducted by Niklassen et al. [17], Huart et al. [18] showed that patients infected with COVID-19 have worse global, sweet and bitter gustatory scores $(p=0$, $0015 ; \mathrm{p}=0,026$ and $\mathrm{p}=0,001)$, suggesting a possible involvement of central olfactory structures and therefore a neuroinvasive nature of SARS-CoV-2. However, a definitive generalization of these results is due to a small cohort not possible.

Although the beforementioned studies stipulate a principal link between COVID-19 and OGD, no study can reliably compare the degree of existing OGD in patients before and after a SARS-CoV-2 infection. A high prevalence of OGD was also found in diverse studies [11, 19, 20], e.g., a multicenter European study [21] in which almost $90 \%$ of COVID-19 patients reported olfactory and gustatory dysfunction. Lechien et al. [21] assessed the impact of COVID-19 on olfactory and gustatory dysfunction by using a short version of the Questionnaire of Olfactory Disorders-Negative Statements (sQOD-NS) and the smell and taste component of the National Health and Nutrition Examination Survey. Similarly, Luers et al. [22] used a standardized 2-section questionnaire consisting of demographic data and the total nasal symptom score (TNSS) evaluating for nasal congestion, sneezing, nasal itching, and rhinorrhea. The study indicated a significant relationship between the presence of 
Table 6 Presence of symptoms in COVID-19 negative tested patients with olfactory and gustatory dysfunction (binary scaled)

\begin{tabular}{|c|c|c|c|}
\hline Variable & COVID-19 Negative with OGD & COVID-19 Negative without OGD & $p$-value \\
\hline Number of Patients & 184 & 484 & \\
\hline Fever $\left(37.5^{\circ} \mathrm{C}\right)$ & 80 (43.48\%) & $134(27.69 \%)$ & 0.0104 \\
\hline Visual Dysfunction & 39 (21.20\%) & $41(8.47 \%)$ & 0.0001 \\
\hline Auditory Dysfunction & $37(20.11 \%)$ & $18(3.72 \%)$ & 0.0001 \\
\hline Sensibility Dysfunction & $38(20.65 \%)$ & 49 (10.12\%) & 0.0001 \\
\hline Dyspnoea & $114(61.96 \%)$ & $153(31.61 \%)$ & 0.0001 \\
\hline Fatigue & $165(89.67 \%)$ & 301 (62.19\%) & 0.0001 \\
\hline Headache & $153(83.15 \%)$ & $266(54.96 \%)$ & 0.0001 \\
\hline Joint Pain & $132(71.74 \%)$ & $177(36.57 \%)$ & 0.0001 \\
\hline Rhinorrhea & $132(71.74 \%)$ & $220(45.45 \%)$ & 0.0001 \\
\hline Cough & $139(75.54 \%)$ & $239(49.38 \%)$ & 0.0001 \\
\hline Pharyngitis & $140(76.09 \%)$ & $220(45.45 \%)$ & 0.0001 \\
\hline Diarrhea & 77 (41.85\%) & $100(20.66 \%)$ & 0.0001 \\
\hline Ocular Pruritus & 71 (38.59\%) & $140(28.93 \%)$ & 0.0176 \\
\hline \multicolumn{4}{|l|}{ Medication } \\
\hline General use of medication & 82 (44.57\%) & 163 (33.68\%) & 0.0091 \\
\hline Ibuprofen & 45 (24.46\%) & 92 (19.01\%) & 0.1192 \\
\hline Acetaminophen & 31 (16.85\%) & 59 (12.19\%) & 0.1152 \\
\hline Aspirin & 9 (4.89\%) & $16(3.31 \%)$ & 0.3348 \\
\hline Metamizole & $12(6.5 \%)$ & 9 (1.86\%) & 0.0020 \\
\hline Diclofenac & $1(0.54 \%)$ & 0 & 0.2754 \\
\hline Ketoprofen & $1(0.54 \%)$ & 0 & 0.2754 \\
\hline Other medication & 11 (5.98\%) & 18 (3.72\%) & 0.2005 \\
\hline \multicolumn{4}{|c|}{ Pre-existent diseases in COVID-19 negative tested patients with olfactory and gustatory dysfunction (binary scaled) } \\
\hline Pre-existent disease & $109(59.24 \%)$ & $322(66.53 \%)$ & 0.0314 \\
\hline Stroke & 0 & $2(0.41 \%)$ & 1.0000 \\
\hline Myocardial Infarction & $4(2.17 \%)$ & $5(1.03 \%)$ & 0.2690 \\
\hline Chronic heart disease & $8(4.35 \%)$ & $15(3.10 \%)$ & 0.4291 \\
\hline Rheumatological disease & $7(3.80 \%)$ & $7(1.45 \%)$ & 0.0706 \\
\hline Transplantation & 0 & $3(0.62 \%)$ & 0.5651 \\
\hline Kidney disease & $2(1.09 \%)$ & $1(0.21 \%)$ & 0.1854 \\
\hline Dialysis & 0 & 0 & n.a \\
\hline Autoimmune liver disease & 0 & $1(0.21 \%)$ & 1.0000 \\
\hline Liver cirrhosis & $1(0.54 \%)$ & $1(0.21 \%)$ & 0.4753 \\
\hline Lung disease & $23(12.50 \%)$ & 49 (10.12\%) & 0.3763 \\
\hline Lupus & 0 & $2(0.41 \%)$ & 1.0000 \\
\hline other & $52(28.26 \%)$ & 108 (22.31\%) & 0.1077 \\
\hline
\end{tabular}

reduced olfaction and a reduced sense of taste $(P<.001)$. Furthermore, recent studies suggested that the presence of self-reported olfactory and gustatory dysfunction had a high specificity as a screening criterion for COVID-19 [23] (98.7, 95\% CI 97.6-99.4\%) and correlated with a milder course of infection [24]. Similarly, our study indicated a significantly higher prevalence of olfactory
(58.1\%) and gustatory dysfunction (62.8\%) (each $p<0.0001)$ and significantly longer median duration of olfactory disturbance $(p=0.0010)$ compared to SARS$\mathrm{CoV}-2$ negative tested patients.

Nevertheless, more than $20 \%$ of SARS-CoV-2 negative tested individuals in our study reported OGD. This may be critical to proceedings in diagnosis and treatment of 
COVID-19 as currently no recommendation on how to proceed with SARS-CoV-2 negative tested individuals is available. Although robust data are lacking one could assume that these individuals displaying severe olfactory and gustatory dysfunction as loss of smell and taste may have a higher chance of false negative tests as OGD was reported to serve as a potential predictor of infection [25-28].

In light of the increased awareness of OGD as a symptom of COVID-19 created by mainstream media, potential contributory factors like other diseases, medicationor allergies have to be taken into closer consideration. In addition, the general prevalence of olfactory and gustatory impairment is not well established.

Medications like acetaminophen and ibuprofen can cause olfactory and gustatory dysfunction although these side effects are reported rarely [29] and are especially more prevalent in older patients in conjunction with the use of other medication for chronic conditions [30]. Other viral infections might also be associated with olfactory and gustatory dysfunction [31]. The influenza virus is known to cause hyposmia and hypogeusia [32], but recent epidemiological data from Germany indicates that the influenza virus was virtually non-existent in April and subsequent months [33]. Additionally, we included questions assessing concomitant use of antiinflammatory medication as the onset of taste or smell dysfunction could coincide with the introduction of a new drug or drug combination [5]. Patients infected with COVID-19 tended to use more anti-inflammatory medication compared to COVID-19 negative tested individuals with statistical difference in the use of acetaminophen $(p=0.0025)$ and metamizole $(p=$ 0.0039). Therefore, our study indicates that use of concomitant medication may have a contributory effect in patients tested positive for SARS-CoV-2 reporting OGD, as a statistical significance in the mean number of taste disturbances was evident in the SARS-CoV-2 positive tested subgroup ( $\mu$ in changes of taste 0.8 versus 0.3 ; $p<0.0001)$. In addition, pre-existing olfactory and gustatory dysfunction are possibly more likely in older male patients $[5,30]$, in patients with upper airway inflammation (allergic rhinitis, rhinosinusitis) [34] or in patients with neurodegenerative disorders [35]. Our analysis indicated that OGD was more commonly recognized as a symptom in the younger population. More females displayed symptoms of gustatory dysfunction $(29.8 \%, p=$ $0.0041)$ and olfactory dysfunction $(22.9 \%, p=0.0174)$ compared to man. Additionally, the simultaneous occurrence of OGD was more prevalent in females (33.08\%) than males (23.96\%) with statistical significance in younger patients.

Our data indicates that a statistical difference in the number of pre-existing diseases was present in COVID-
19 negative tested patients with OGD $(\mathrm{p}=0$. 0314). Similarly, COVID-19 positive tested patients had more pre-existent diseases with statistical significance in kidney disease $(p=0.0004$,$) which potentially could contrib-$ ute to the presence of OGD $[9,36]$. Other possible causes for altered olfaction and gustation include upper airway inflammation (e.g allergic rhinitis, chronic rhinosinusitis with or without nasal polyps) [34, 37]. Allergic rhinitis is a common, underdiagnosed disorder which can affect people of all ages and is associated with symptoms like pruritis, rhinorrhea and nasal congestion [6, 38 ]. Recent research indicates that over the last 20 years, a significant rise in the total number of weed pollen sensitization, especially in younger patients took place in Germany [39]. Our study indicates that patients tested negative for COVID-19 who displayed OGD more commonly reported allergy-like features like rhinorrhea $(72 \%, p=0.0001)$ and ocular pruritus $(39 \%, p=0.0164)$ compared to negative tested patients without OGD $(\mathrm{p}=$ 0.0001), indicating a possible allergic component which could coincide with the COVID-19 pandemic.

We acknowledge several limitations to our study. First, our study contains a relatively small amount of COVID19 positive tested individuals. Furthermore, no psychophysical evaluation of smell and taste was conducted. Recent studies [40] indicate that an olfactory disorder in COVID-19 patients is much more prevalent than those detected by questionnaires and use of objective methods are useful tools to discriminate between these patients. That would imply that the self-reported OGD of more than $20 \%$ in our SARS-CoV-2 negative tested individuals are severely underestimated. So the correlation between OGD and different disease processes remains to be further enlightened. One can speculate about the different etiologies for OGD, but this study indicates that the global COVID-19 pandemic and our findings in COVID-19 negative-tested individuals merit deeper investigation in these disturbances in the future.

\section{Conclusion}

Overall, when characterizing the course of COVID-19 disease in Germany, the most common symptoms among individuals who tested positive for COVID-19 were fatigue, headache, and cough. Additionally, olfactory and gustatory dysfunction were also reported by many COVID-19 negative individuals who more commonly reported allergy-like features like rhinorrhea $(72 \%, p=0.0001)$ and ocular pruritus $(39 \%, p=0.0164)$ indicating a possible allergic component that could coincide with the COVID-19 pandemic.

More females displayed symptoms of gustatory dysfunction $(29.8 \%, p=0.0041)$ and olfactory dysfunction (22.9\%, $p=0.0174)$ compared to males. Thus, bringing early COVID-19 tests to the populations at risk must be a main focus for the upcoming months. 


\section{Supplementary Information}

The online version contains supplementary material available at https://doi. org/10.1186/s12879-021-06294-2.

\section{Additional file 1.}

\section{Acknowledgements}

ME and AT were supported by the Ministry of Science, Research and Arts of the State of Baden-Wuerttemberg to establish a clinical cooperation unit healthy metabolism at the Center of Prevention and Digital Medicine Baden Wuerttemberg as well as for the Baden-Württemberg Center for Digital Detection and Prevention of common diseases (BW-ZDFP). AT received funding from the Sino-German Center for Research Promotion (German Research Foundation (DFG) and the National Natural Science Foundation of China (NSFC), Projects C-0012 and GZ-1546).

\section{Authors' contributions}

A.K and A.T wrote the main manuscript text and C.W performed the statistical analysis. A.K and C.W prepared the tables. S.L, A.S and N.R provided input from an ENT-perspective. T.M, N.H, and M.E reviewed the paper critically. M.N, M.G and B.H helped with data collection. All authors reviewed the manuscript. The author(s) read and approved the final manuscript.

\section{Funding}

The authors received no specific funding for this work. Open Access funding enabled and organized by Projekt DEAL.

\section{Availability of data and materials}

All data generated or analysed during this study are included in this published article [and its supplementary information files].

\section{Declarations}

Ethics approval and consent to participate

Ethical approval for this study was obtained from the ethics commission II of the Ruprecht-Karls-University Heidelberg (Medical Faculty Mannheim) on March 27, 2020 (approval number 2020-541 N). Patients were invited to participate and written informed consent was obtained from all subjects prior to the study inclusion. All methods were carried out in accordance with relevant guidelines and regulations.

\section{Consent for publication}

Not applicable.

\section{Competing interests}

The authors declare that they have no competing interests.

\section{Author details}

'Department of Medicine II, University Medical Center Mannheim, Medical Faculty Mannheim, Heidelberg University, Mannheim, Germany. ${ }^{2}$ Clincial Cooperation Unit Healthy Metabolism, Center for Preventive Medicine Baden-Württemberg, Medical Faculty Mannheim, Heidelberg University, Mannheim, Germany. ${ }^{3}$ Department of Statistics, Biomathematics and Information Processing, Heinrich Lanz Center for Digital Health, Medical Faculty Mannheim, Heidelberg University, Mannheim, Germany. Institute of Medical Microbiology and Hygiene, Medical Faculty of Mannheim, University of Heidelberg, Mannheim, Germany. ${ }^{5}$ Mannheim Institute for Innate Immunoscience (MI3), Medical Faculty of Mannheim, Heidelberg University, Mannheim, Germany. ${ }^{6}$ Department of Otorhinolaryngology, Head and Neck Surgery, Medical Faculty Mannheim, Heidelberg University, Mannheim, Germany. ${ }^{7}$ Department of Medicine II, Division of Hepatology, Division of Clinical Bioinformatics, University Medical Center Mannheim, Medical Faculty Mannheim, Heidelberg University, Mannheim, Germany.
Received: 14 February 2021 Accepted: 3 June 2021

Published online: 26 June 2021

\section{References}

1. Gupta A, Madhavan MV, Sehgal K, Nair N, Mahajan S, Sehrawat TS, et al. Extrapulmonary manifestations of COVID-19. Nat Med. 2020;26(7):1017-32. https://doi.org/10.1038/s41591-020-0968-3.

2. Heymann DL, Shindo N. COVID-19: what is next for public health? Lancet. 2020;395(10224):542-5. https://doi.org/10.1016/S0140-6736(20)30374-3.

3. Li Q, Guan X, Wu P, Wang X, Zhou L, Tong Y, et al. Early transmission dynamics in Wuhan, China, of novel coronavirus-infected pneumonia. $N$ Engl J Med. 2020;382(13):1199-207. https://doi.org/10.1056/NEJMoa2001316.

4. Guan WJ, Ni ZY, Hu Y, Liang WH, Ou CQ, He JX, et al. Clinical characteristics of coronavirus disease 2019 in China. N Engl J Med. 2020;382(18):1708-20. https://doi.org/10.1056/NEJMoa2002032.

5. Schiffman SS. Influence of medications on taste and smell. World J Otorhinolaryngol Head Neck Surg. 2018;4(1):84-91. https://doi.org/10.1016/j. wjorl.2018.02.005.

6. Greiner AN, Hellings PW, Rotiroti G, Scadding GK. Allergic rhinitis. Lancet. 2011;378(9809):2112-22. https://doi.org/10.1016/S0140-6736(11)60130-X.

7. Crincoli V, Anelli MG, Quercia E, Piancino MG, Di Comite M. Temporomandibular disorders and Oral features in early rheumatoid arthritis patients: an observational study. Int J Med Sci. 2019;16(2):253-63. https:// doi.org/10.7150/ijms.28361.

8. Etoh S, Kawahira K, Ogata A, Shimodozono M, Tanaka N. Relationship between dysgeusia and dysesthesia in stroke patients. Int J Neurosci. 2008; 118(1):137-47. https://doi.org/10.1080/00207450601044686.

9. McMahon EJ, Campbell KL, Bauer JD. Taste perception in kidney disease and relationship to dietary sodium intake. Appetite. 2014;83:236-41. https:// doi.org/10.1016/j.appet.2014.08.036.

10. Mao L, Jin H, Wang M, Hu Y, Chen S, He Q, et al. Neurologic manifestations of hospitalized patients with coronavirus disease 2019 in Wuhan, China. JAMA Neurol. 2020;77(6):1-9.

11. Luers JC, Rokohl AC, Loreck N, Wawer Matos PA, Augustin M, Dewald F, et al. Olfactory and gustatory dysfunction in coronavirus disease 19 (COVID19). Clin Infect Dis. 2020;71(16):2262-4. https://doi.org/10.1093/cid/ciaa525.

12. Korber B, Fischer WM, Gnanakaran S, Yoon H, Theiler J, Abfalterer W et al. Tracking Changes in SARS-CoV-2 Spike: Evidence that D614G Increases Infectivity of the COVID-19 Virus. Cell. 2020;182(4):812-827.e19. https://doi. org/10.1016/j.cell.2020.06.043

13. Gourtsoyannis Y. Olfactory and Gustatory Symptoms in European COVID-19 Cohorts. Clin Infect Dis. 2020;71(11):3017-8. https://doi.org/10.1093/cid/ciaa 685.

14. Cao Y, Li L, Feng Z, Wan S, Huang P, Sun X, et al. Comparative genetic analysis of the novel coronavirus (2019-nCoV/SARS-CoV-2) receptor ACE2 in different populations. Cell Discov. 2020;6(1):11. https://doi.org/10.1038/ s41421-020-0147-1.

15. Zou X, Chen K, Zou J, Han P, Hao J, Han Z. Single-cell RNA-seq data analysis on the receptor ACE2 expression reveals the potential risk of different human organs vulnerable to 2019-nCoV infection. Front Med. 2020;14(2): 185-92. https://doi.org/10.1007/s11684-020-0754-0.

16. Baig AM, Khaleeg A, Ali U, Syeda H. Evidence of the COVID-19 virus targeting the CNS: tissue distribution, host-virus interaction, and proposed neurotropic mechanisms. ACS Chem Neurosci. 2020;11(7):995-8. https://doi. org/10.1021/acschemneuro.0c00122.

17. Niklassen AS, Draf J, Huart C, Hintschich C, Bocksberger S, Trecca EMC, et al. COVID-19: recovery from chemosensory dysfunction. A multicentre study on smell and taste. Laryngoscope. 2021;131(5):1095-100. https://doi.org/10.1 002/lary.29383.

18. Huart C, Philpott C, Konstantinidis I, Altundag A, Whitcroft KL, Trecca EMC, et al. Comparison of COVID-19 and common cold chemosensory dysfunction. Rhinology. 2020;58(6):623-5. https://doi.org/10.4193/Rhin20.251.

19. Altin F, Cingi C, Uzun T, Bal C. Olfactory and gustatory abnormalities in COVID-19 cases. Eur Arch Otorhinolaryngol. 2020;277(10):2775-2781. https:// doi.org/10.1007/s00405-020-06155-9.

20. Salmon D, Bartier S, Hautefort C, Nguyen Y, Nevoux J, Hamel AL, et al. Selfreported loss of smell without nasal obstruction to identify COVID-19. The multicenter CORANOSMIA cohort study. J Infect. 2020;81(4):614-20. https:// doi.org/10.1016/j.jinf.2020.07.005.

21. Lechien JR, Chiesa-Estomba CM, De Siati DR, Horoi M, Le Bon SD, Rodriguez A, et al. Olfactory and gustatory dysfunctions as a clinical presentation of 
mild-to-moderate forms of the coronavirus disease (COVID-19): a multicenter European study. Eur Arch Otorhinolaryngol. 2020;277(8):225161. https://doi.org/10.1007/s00405-020-05965-1.

22. Luers JC, Rokohl AC, Loreck N, Wawer Matos PA, Augustin M, Dewald F, et al. Olfactory and gustatory dysfunction in coronavirus disease 2019 (COVID-19). Clin Infect Dis. 2020;71(16):2262-4. https://doi.org/10.1093/cid/ ciaa525.

23. Wee LE, Chan YFZ, Teo NWY, Cherng BPZ, Thien SY, Wong HM, et al. The role of self-reported olfactory and gustatory dysfunction as a screening criterion for suspected COVID-19. Eur Arch Otorhinolaryngol. 2020;277(8): 2389-90. https://doi.org/10.1007/s00405-020-05999-5.

24. Yan CH, Faraji F, Prajapati DP, Ostrander BT, DeConde AS. Self-reported olfactory loss associates with outpatient clinical course in COVID-19. Int Forum Allergy Rhinol. 2020;10(7):821-31. https://doi.org/10.1002/alr.22592.

25. Menni C, Valdes AM, Freidin MB, Sudre $\mathrm{CH}$, Nguyen $\mathrm{LH}$, Drew DA, et al. Real-time tracking of self-reported symptoms to predict potential COVID-19. Nat Med. 2020;26(7):1037-40. https://doi.org/10.1038/s41591-020-0916-2.

26. Arevalo-Rodriguez I, Buitrago-Garcia D, Simancas-Racines D, ZambranoAchig P, Del Campo R, Ciapponi A, et al. False-negative results of initial RTPCR assays for COVID-19: A systematic review. PLoS One. 2020;15(12): e0242958. https://doi.org/10.1371/journal.pone.0242958.

27. Woloshin S, Patel N, Kesselheim AS. False negative tests for SARS-CoV-2 infection - challenges and implications. N Engl J Med. 2020;383(6):e38. https://doi.org/10.1056/NEJMp2015897.

28. Lisboa Bastos M, Tavaziva G, Abidi SK, Campbell JR, Haraoui LP, Johnston JC, et al. Diagnostic accuracy of serological tests for covid-19: systematic review and meta-analysis. BMJ. 2020;370:m2516.

29. Lötsch J, Knothe C, Lippmann C, Ultsch A, Hummel T, Walter C. Olfactory drug effects approached from human-derived data. Drug Discov Today. 2015;20(11):1398-406. https://doi.org/10.1016/j.drudis.2015.06.012.

30. Schiffman SS, Zervakis J. Taste and smell perception in the elderly: effect of medications and disease. Adv Food Nutr Res. 2002:44:247-346. https://doi. org/10.1016/S1043-4526(02)44006-5.

31. Stuck BA, Hummel T. Olfaction in allergic rhinitis: a systematic review. J Allergy Clin Immunol. 2015;136(6):1460-70. https://doi.org/10.1016/j.jaci.201 5.08.003.

32. Henkin RI, Levy LM, Fordyce A. Taste and smell function in chronic disease: a review of clinical and biochemical evaluations of taste and smell dysfunction in over 5000 patients at the taste and smell Clinic in Washington, DC. Am J Otolaryngol. 2013;34(5):477-89. https://doi.org/10.101 6/j.amjoto.2013.04.006

33. Robert Koch Institute. Weekly Influenza Report [Influenza -Wochenbericht]. https://influenza.rki.de/Wochenberichte.aspx. Accessed 24 June 2021.

34. Jaume F, Quintó L, Alobid I, Mullol J. Overuse of diagnostic tools and medications in acute rhinosinusitis in Spain: a population-based study (the PROSINUS study). BMJ Open. 2018;8(1):e018788. https://doi.org/10.1136/ bmjopen-2017-018788.

35. Marin C, Vilas D, Langdon C, Alobid I, López-Chacón M, Haehner A, et al. Olfactory dysfunction in neurodegenerative diseases. Curr Allergy Asthma Rep. 2018;18(8):42. https://doi.org/10.1007/s11882-018-0796-4.

36. Manley KJ. Taste genetics and gastrointestinal symptoms experienced in chronic kidney disease. Eur J Clin Nutr. 2015;69(7):781-5. https://doi.org/10.1 038/ejcn.2015.80.

37. Guss J, Doghramji L, Reger C, Chiu AG. Olfactory dysfunction in allergic rhinitis. ORL J Otorhinolaryngol Relat Spec. 2009;71(5):268-72. https://doi. org/10.1159/000242429.

38. Scadding GK, Hellings PW, Bachert C, Bjermer L, Diamant Z, Gevaert P, et al. Allergic respiratory disease care in the COVID-19 era: a EUFOREA statement. World Allergy Organ J. 2020;13(5):100124.

39. Forkel S, Beutner C, Heetfeld A, Fuchs T, Schön MP, Geier J, et al. Allergic rhinitis to weed pollen in Germany: dominance by plantain, rising prevalence, and Polysensitization rates over 20 years. Int Arch Allergy Immunol. 2020;181(2):128-35. https://doi.org/10.1159/000504297.

40. Gözen ED, Aliyeva C, Tevetoğlu F, Karaali R, Balkan I, Yener HM, et al. Evaluation of Olfactory Function With Objective Tests in COVID-19-Positive Patients: A Cross-Sectional Study. Ear Nose Throat J. 2021;100(2_suppl):169s-73s.

\section{Publisher's Note}

Springer Nature remains neutral with regard to jurisdictional claims in published maps and institutional affiliations.

\section{Ready to submit your research? Choose BMC and benefit from:}

- fast, convenient online submission

- thorough peer review by experienced researchers in your field

- rapid publication on acceptance

- support for research data, including large and complex data types

- gold Open Access which fosters wider collaboration and increased citations

- maximum visibility for your research: over $100 \mathrm{M}$ website views per year

At BMC, research is always in progress.

Learn more biomedcentral.com/submissions 